\title{
Autonomy - A leading principle in the end-of-life decision making?
}

\author{
Helena Peterkovás \\ Centre for Medical Law, Law Faculty, Charles University in Prague, Czech Republic \\ Correspondence: Helena Peterková. Address: Centre for Medical Law, Law Faculty, Charles University in Prague, nám. \\ Curieových 7, 11640 Praha 1, Czech Republic. E-mail: helenpeterkova@seznam.cz \\ Received: August 1, 2013 \\ DOI : $10.5430 /$ jha.v3n2p19 \\ Accepted: October 9, 2013 \\ Online Published: October 29, 2013
}

\section{Abstract}

Objective: The objective of this paper is to introduce some of the most specific legal regulations on informed consent and patient's will and to show the limits of the recognition of patient's autonomy, especially as the end-of-life issues are regarded. Autonomy of a competent patient is often presented as an overwhelming argument in the end-of-life debate, regardless whether in the context of life termination on request or in the decision making about withdrawal or withholding of the treatment.

Despite of the general opinion, that decriminalization of life termination on request is legitimately based on the respect for the patient's wishes to die, even in the world most liberal end-of-life law of Benelux countries the legal concept seems to be built in a considerably different and more sophisticated way, as it does not solely rely on the request of the patient to be administered the lethal dose.

Basically, the will of a competent patient to be let die is to be understood as a reason for the doctors to omit the further medical treatment, even if this omission leads to death of the patient. To the contrary, no actively caused death, as well as actively caused grievous injuries which are not a result of an acknowledged proper treatment, can be pleaded lawful with the reference to the consent of the patient.

With this paper, the extent of exercising patient's autonomy concerning the specific law on euthanasia in some European countries was examined to show on these examples the perhaps too overestimated factual impact of the autonomy principle in the medical law.

Methods: Whilst comparing the most liberal legal systems in the world (among others the Swiss and Dutch ones) in which either life termination on request and/or assisted suicide was conditionally decriminalised, a critical analysis was performed to show to what extent and under which circumstances represents the will of a competent patient a defence to a doctor who provided the patient with life termination on request or assisted suicide or let the patient die.

Results: According to the analysis, in no legal jurisdiction in the world the will (incl. consent and request) of the patient as such can serve as a full defence; for decriminalisation of the life termination on request or assisted suicide the fulfilment of other criteria must be reached.

Conclusions: Although the will of the patient can with no doubt be understood as a conditio sine qua non for decriminalisation of life termination on request and/or assisted suicide, without being accomplished with other legal 
requirements it cannot be pleaded as full defence. Therefore, as the area of end-of-life decision making is concerned, the primacy of principle of autonomy should not be automatically taken for granted.

\section{Key words}

Autonomy, End-of-life decisions, Decriminalisation of life termination on request and assisted suicide, Defence

\section{Introduction}

Autonomy, as a bioethical concept of the self-determination of a competent patient, has been recognised - as an immanent element of the right to personal freedom, dignity, private life - via many international human rights conventions. However, it still seems to remain a phenomenon typical mainly of the most developed (i.e. so-called "Western") cultures. Autonomy poses neither a unified content nor a distinct extent worldwide; indeed, the legal framework defining the area for exercising one's autonomy is to be regarded as an entirely national matter, taking into account the unique domestic historical and social background and public interest of the relevant country ${ }^{[1]}$.

The principle of a patient's autonomy in the context of providing medical treatment - of course to some extent deservedly - is widely honoured and considered to be a generally predominant one. This principle has its reflection as well in the end-of-life decision's debate, where the autonomous will of the person demanding death is regarded in particular as a potentially adequate argument for the decriminalisation of life termination of request or assisted suicide.

Nevertheless, even in the most liberal countries in the world it can be assumed that autonomy should not be understood as a mere enforcement of one's wishes, but as the ability to make rational and mature (therefore also respectable) decisions ${ }^{[2]}$. According to the analyses of the national laws on life termination on request and assisted suicide and even more according to the comparison of the national laws on advanced directives, it is precisely the evaluation of the rationality of the will of the patient which appears to provide the possibility of treating a patient in a paternalistic way, despite his/her right to autonomy.

One of the most crucial difficulties attached to autonomy is undoubtedly the legally guaranteed respect towards it under circumstances in which one's own health or even life could be at risk by exercising the autonomy. Although the self-harm or (attempted) suicide of a mentally healthy, competent person - with the great exceptions such as intended insurance fraud, avoiding military service, financial gain (sale of own kidney) etc. - shall not in principle be sanctioned by law, the law constructs much stricter conditions for the impunity of the active conduct of a third person resulting in the same destructive effect.

\section{Comparative analysis}

As the criminal liability is regarded, it is constructed specifically by every national law. In the end-of-life debate, the concept of patient's will to die as a potential defence for offender's action makes the crucial difference between the most liberal legal systems and those where termination of life upon request and/or assisted suicide remain a criminal offence.

Surprisingly, the national laws do not differ that extremely as the consent of a victim to a grievous bodily harm (as a less serious result in comparison to death) is concerned: Regardless whether the life termination on request or assisted suicide was decriminalised, the consent of an injured person to intentionally caused grievous bodily harm will be hardly ever recognised as a (criminal) defence, unless there is a good (public) reason for approving the activity of the offender typically, the injury is a consequence of a proper medical treatment carried out with due professional care.

This rule could be found across all the countries where informed consent has been established as a prerequisite for a medical intervention. According to S. 228 of the German Criminal Code, the consent of a grievously injured person could 
only be legally relevant and effective if the act - even with the consent of the injured person - is not contrary to good morals. In England and Wales, the consent of a victim matters either in cases of proper medical treatment, properly conducted games and tattoos and piercing, or in cases of unintentional bodily harm where only the risk of harm could be consented ${ }^{[3]}$. According to S. 30 Para 3 of the Czech Criminal Code, the consent of the person concerned to bodily harm or death is not to be considered as a defence, except of a medical intervention which corresponds in the relevant time to the standards of clinical practice as well as to the legal system. In Switzerland, the offence of wounding (i.e. non-grievous harm: Einfache Körperverletzung) is under Art. 123 Para 1 of the Swiss Criminal Code to be prosecuted only on the request of the aggrieved person. Thus, a non-grievous harm can be justified by the patient's consent, and even by a posteriori given one, because it depends only on the will of the person concerned (in most cases, the patient), whether he or she will or will not afterwards initiate criminal proceedings in a statutory period. By contrast, if there is a grievous bodily harm which does not occur as a result of a proper medical treatment, then the consent of the victim to such an injury does only exceptionally serve a legally relevant justification to the offender. Even in Netherlands, Belgium and Luxembourg the decriminalisation of life termination on request and/or assisted suicide was reached by enacting specific laws, instead of claiming the consent of a victim to physical harm to be a general defence.

At this point it could be seen clearly, that an autonomous will of the victim as such has definitely its limits as the inviolability of physical integrity is regarded. The more it shall be pleaded insufficient when not the invasion against the health but against the life of another person takes places.

Only in three countries in the world (the Netherlands, Belgium and Luxembourg; further referred to in the text as the Benelux countries), life termination on request would not - by satisfying specific statutory conditions - be prosecuted as a homicide. Although the Benelux Euthanasia Law has introduced an entire catalogue of requirements for decriminalised life termination on request and assisted suicide respectively (it should be provided in cases of incurable disease, after consultation with another independent physician and after consideration of available alternatives), it could be deduced, particularly from the published annual reports of the Dutch Regional Euthanasia Review Committees ${ }^{[4]}$, that in fact solely the requirements of competent request and unbearable suffering can suffice as being in compliance with the decriminalising Euthanasia Law and must never be absent in any case. The rest of the criteria are interpreted in a quite flexible way by the Regional Euthanasia Review Committees, with the greatest generosity in favour of the attending physician.

\section{Results}

It should be emphasised most clearly that the impunity of a physician providing life termination on request or assisted suicide is not to be derived from the consent (within the meaning of criminal defence) of a patient (a victim from the criminal law point of view) irrespective of how much the patient wants to die. Firstly, albeit both consent and request express the positive inner will of the patient towards an act of the physician and they both must fulfil almost the same legal requirements (i.e. a prior medical explanation regarding the risks and available alternatives ${ }^{[5]}$ ), the distinction between them should not be forgotten: a request demands much more of a pro-active approach on the side of the patient than his or her consent, which in fact would be simply legally insufficient for life termination on request.

Secondly, even the repeatedly voiced desire of a patient to have his or her own life terminated cannot itself justify the action of another person if, in addition to the request, there are other statutory requirements missing. In the Netherlands, the impunity of life termination on request has been constructed by the Dutch courts since the 1980s as a solution of the conflict between the professional duty of a physician to relieve extreme unbearable pain and discomfort and the prohibition of homicide, whilst the physician was centred in this situation by vis maior under Art. Forty of the Dutch Criminal Code ${ }^{[6]}$. The request for termination of life or for assistance in suicide is therefore a fundamental condition for the application of the decriminalising Euthanasia Law, as well as for the potential judgment about the impunity of an attending physician, but it is legally not intended as a criminal defence. 
It is often pointed out that the legal distinction between life termination on request (decriminalised in the Benelux countries) and assisted suicide (explicitly or implicitly decriminalised in, among others, the Netherlands, Luxembourg, some states of the USA, Switzerland, the UK, Germany) is actually for those wanting death discriminatory, because if the physical condition of a patient does not, even with the assistance of a third person ${ }^{[7]}$, allow him/her to kill him/herself, the patient is forced to live (and suffer) further, till the death occurs from another reasons. In favour of decriminalising the life termination on request in countries where assisted suicide has already been decriminalised, it is argued that killing a patient at his/her request is nothing other than an executed assisted suicide, because it is not the third person but the patient who determines the purpose of this act ${ }^{[8]}$.

Nevertheless, it is a reasonable question whether the non-interference of a liberal state in the considered self-harm or suicide of a competent person should not be rethought slightly, when another person is requested to terminate the life of a person. Obviously, the criminal law is not only there to protect the requesting person, but also to legitimately prevent the requested person from playing a crucial role in one of the most dramatic situations in human life - the killing of another human being.

In this context, one can claim that the law has reached an apparently irrational conclusion, when a patient can choose to die slowly and painfully, by refusing nourishment, life-sustaining measures, resuscitation, but cannot choose a quick, painless death, which could without great difficulty technically be brought about by a physician ${ }^{[9]}$. Indeed, the legitimacy of the dichotomy of legal and accepted passive euthanasia (based on withdrawal or withholding of medical treatment, incl. hydration and nutrition) and in principle illegal active euthanasia (i.e. life termination on request) seems to be undermined by this kind of argument, especially when the distinction between passive omission and active commission is sometimes drawn - perhaps because of teleological reasons - in quite an unconvincing way ${ }^{[10]}$. However, it can still be explained in the debate that by withdrawing and withholding medical treatment, including artificial nutrition and hydration, it is the fatal progress of the illness which causes the (more or less) natural death - the patient is left to die, instead of being killed. Alike the commission by life termination on request, in most Western countries the omission of a physician to provide even life-sustaining measures because of the lack of consent of the patient is appreciated, at least in the doctrine.

A most fascinating clinical practice is to be found in the context of providing medical care, which, in order to ignore an autonomous decision of a patient, undermines the competence of the patient, as can very clearly be shown on the examples of minor patients ("they are not mature enough", "they cannot understand the real danger", etc. ${ }^{[11]}$ ), and in the careful application of advance directives ("the patient could not have imagined the future precisely"/"must have been confused at the time of expressing his advance wishes", "it is not in his best interests now to be treated according to his advance directives", etc.).

At this point, therefore, a decision is to be made whether and how autonomy depends on competence and what kind of consequences it has. There are no doubt many entirely autonomous acts of adults which, in the eyes of society, do not deserve any respect at all and which have even been proclaimed as criminal offences, prosecuted and punished. That is why the link between autonomy, competence and respect for the autonomous decision of a competent patient does not need to be necessarily established; respect for autonomy exercised in the area of health can similarly be freely prevailed on by other social interests and principles ${ }^{[12]}$.

\section{Conclusion}

Decision-making about a patient at the end of his or her life should indubitably be a holistic one, regarding the autonomous will of the patient as an unavoidable crucial piece of the patchwork. However it should not be pretended that autonomy is - or even that it should be - the one and only element which matters. After all, even one of the greatest autonomists, Ronald Dworkin, admits that a terminally ill patient could prefer not to be asked whether his or her life should be terminated; The patient could prefer never to have the right to request death ${ }^{[13]}$. 


\section{Conflict of interests}

The author declares that she has no conflicts of interests.

\section{Acknowledgement}

This paper could be written and presented on the 19th World Congress on Medical Law in Maceio, Brazil, thanks to the financial support received from the Grant Agency of Charles University in Prague, Project No. GAUK 6506/2012.

\section{References}

[1] Pretty v UK (Application 2349/02).

[2] SCHMITT, H. Ist die Schweiz mehrheitlich für die aktive Sterbehilfe? In Jusletter 21. März 2011.

[3] R v Brown, et al. 1993; 2 All ER 75; R v Wilson. 1996; 3 WLR 125; R v Billinghurst. 1978; Crim LR 553 etc.

[4] The annual reports of the Dutch Regional Euthanasia Review Committees are to be found at: http://www.euthanasiecommissie.nl/overdetoetsingscommissies/jaarverslag/. The Dutch Euthanasia Law should be considered as an example for Belgian and Luxembourg legislators.

[5] Art. 5 of the Convention on Human Rights and Biomedicine compared to S. 1 Dutch Termination of Life on Request and Assisted Suicide Act.

[6] FENIGSEN R. A case against Dutch euthanasia. A Special Supplement, January / February 1989, Hastings Center Report, p. 23.

[7] The argumentation of Dianne Pretty In.Pretty v UK (Application 2349/02), or Tony Niklinson who suffered from locked-in syndrome. In. http://www.bbc.co.uk/news/uk-17336774.

[8] GÜNTHER, J. Tötung auf Verlangen, Euthanasie und Strafrechtssystem. Bayerische Akademie der Wissenschaften, München, 1998; p: 35.

[9] DWORKIN, R. M. Life's dominion: an argument about abortion and euthanasia, London: Harper Collins, 1993 ; p: 184.

[10] Re A. (children) (conjoined twins: surgical separation) 2000; Lloyd's Rep Med 425.

[11] Re S. (A Minor) (Consent to Medical Treatment) 1994; 2 FLR 1065, Re E (A Minor) (Wardship: Medical Treatment) 1993; 1 FLR 386, Green 292 A 2d 387.

[12] Beneficience, Non-Maleficence, Justice. In FOSTER, Ch. Choosing Life, Choosing Death. The Tyranny of Autonomy in Medical Ethics and Law, Hart, 2009; p: 17-18.

[13] DWORKIN, R. Life’s Dominion. An Argument about Abortion and Euthanasia. London: Harper Collins, 1993 ; p: 190. 